\title{
tBid induces alterations of mitochondrial fatty acid oxidation flux by malonyl-CoA-independent inhibition of carnitine palmitoyltransferase-1
}

\author{
A Giordano ${ }^{1}, \mathrm{M}$ Calvani ${ }^{2}, 0$ Petillo ${ }^{1}$, P Grippo ${ }^{3}$, F Tuccillo, \\ MAB Melone ${ }^{4}$, P Bonelli ${ }^{5}$, A Calarco ${ }^{1}$ and G Peluso ${ }^{*, 1}$ \\ 1 Institute of Protein Biochemistry - IBP, CNR, Naples, Italy; \\ 2 Scientific Department - Sigma-Tau, Pomezia, Rome, Italy; \\ ${ }^{3}$ Department of Experimental Medicine, School of Medicine, Second University \\ of Naples, Naples, Italy; \\ 4 Institute of Neurological Science, School of Medicine, Second University of \\ Naples, Naples, Italy; \\ ${ }^{5}$ National Cancer Institute - INT 'Fondazione G Pascale', Naples, Italy \\ * Corresponding author: G Peluso, Institute of Protein Biochemistry - IBP, CNR, \\ Via Pietro Castellino, 111, Naples 80131, Italy. Tel: + 39-081-6132280; \\ Fax: + 39-081-6132277; E-mail: g.peluso@ ibp.cnr.it
}

Received 14.10.04; revised 24.2.05; accepted 03.3.05; published online 22.4.05 Edited by $\mathrm{P}$ Vandenabeele

\begin{abstract}
Recent studies suggest a close relationship between cell metabolism and apoptosis. We have evaluated changes in lipid metabolism on permeabilized hepatocytes treated with truncated Bid (tBid) in the presence of caspase inhibitors and exogenous cytochrome $c$. The measurement of $\beta$-oxidation flux by labeled palmitate demonstrates that tBid inhibits $\beta$-oxidation, thereby resulting in the accumulation of palmitoyl-coenzyme $\mathbf{A}$ (CoA) and depletion of acetyl-carnitine and acylcarnitines, which is pathognomonic for inhibition of carnitine palmitoyltransferase-1 (CPT-1). We also show that tBid decreases CPT-1 activity by a mechanism independent of both malonyl-CoA, the key inhibitory molecule of CPT-1, and Bak and/or Bax, but dependent on cardiolipin decrease. Overexpression of Bcl-2, which is able to interact with CPT-1, counteracts the effects exerted by tBid on $\beta$-oxidation. The unexpected role of tBid in the regulation of lipid $\beta$-oxidation suggests a model in which tBid-induced metabolic decline leads to the accumulation of toxic lipid metabolites such as palmitoyl-CoA, which might become participants in the apoptotic pathway.

Cell Death and Differentiation (2005) 12, 603-613.

doi:10.1038/sj.cdd.4401636

Published online 22 April 2005
\end{abstract}

Keywords: tBID; $\beta$-oxidation; malonyl-CoA; CPT-1; mitochondria

Abbreviations: CPT-1, carnitine palmitoyltransferase-1; CPT-2, carnitine palmitoyltransferase-2; CoA, coenzyme A; tBid, truncated Bid; $\Delta \Psi_{m}$, mitochondrial transmembrane potential; siRNA, small interfering RNA; zVAD-fmk, $N$-benzyloxycarbonyl-Val-AlaAspfluoromethyl ketone; PMSF, phenyl methyl sulfonyl fluoride; TMRE, tetramethylrhodamine ethyl ester; COX4, cytochrome $c$ oxidase polypeptide IV; $\mathrm{BMH}$, bismaleimidohexane

\section{Introduction}

As a powerhouse of energy, the mitochondria serve to produce cellular energy. ${ }^{1}$ During this process, acetyl-coenzyme $A(C \circ A)$, the breakdown product of fatty acids and glucose, is passed through the Kreb's cycle to generate electrons. These, in turn, are transferred to the proteins of the respiratory chain in the inner mitochondrial membrane, generating the mitochondrial transmembrane potential $\left(\Delta \Psi_{\mathrm{m}}\right)$, which results from an asymmetric distribution of protons on both sides of the inner mitochondrial membrane. The $\Delta \Psi_{\mathrm{m}}$ creates an electrochemical gradient, which is used to produce ATP.

In addition to serving as the main intracellular source of energy of the cell, mitochondria regulate several cellular processes that are linked to apoptosis. ${ }^{2}$ They are indeed the storage site for a number of soluble factors that mediate apoptosis, including cytochrome $c$, certain procaspases and apoptosis-inducing factor. ${ }^{3}$ Mitochondria can activate apoptosis by releasing these factors from their intermembrane space into the cytoplasm. The relocalization of these mitochondrial proteins results in the direct activation of caspases, the neutralization of cytosolic caspase inhibitors and the activation of nucleases.

Recent studies suggest a more intimate integration of cellular energy metabolism and apoptosis. Changes in either glycolytic or lipid metabolism are sufficient to cause commitment to programmed cell death and can directly induce decisive disruption of mitochondrial function and collapse of the $\Delta \Psi_{\mathrm{m}}$. For example, cellular glycolysis may be restricted by decreasing the glucose level in the medium. Severe restrictions in glycolysis result in cell death also in the presence of prosurvival growth factors. Surprisingly, death as a result of reducing the concentration of glucose proceeds via apoptosis because it induces the activation of Bid, the release of cytochrome $c$ and the activation of caspases. ${ }^{4}$ Again, palmitate and similar saturated long-chain acyl fatty acids are also known to induce apoptosis via a mechanism that is not completely elucidated. ${ }^{5}$ It has been described that palmitate can determine the generation of ceramide, a proapoptotic second messenger, via a pathway that is stimulated by pharmacological inhibition of carnitine palmitoyltransferase-1 (CPT-1). ${ }^{6}$

Moreover, it is becoming increasingly clear that not only cellular metabolism plays an important regulatory role in the control of programmed cell death but also elements of the apoptotic machinery can affect the cellular metabolism. Interestingly, several papers have demonstrated that truncated Bid (tBid) elicits dissociation, from mitochondria, of hexokinases (HK), enzymes catalyzing the phosphorylation of glucose, the first committed step of glucose metabolism. ${ }^{4}$ Activated serine/threonine kinase Akt/protein kinase B hinders the proapoptotic activity of tBid by coupling of glucose 
metabolism to oxidative phosphorylation and by regulating PT pore opening favoring the HK interaction with the outer mitochondrial membrane. ${ }^{4-7}$

Less is known about the connection between tBid-mediated mitochondrial dysfunction and fatty acid metabolism. In particular, it is uncertain whether tBid-induced mitochondrial $\beta$-oxidation perturbations result exclusively from the loss of cytochrome $c$ or whether other irreversible events occur. Finally, there are no data about the appearance, in cells exposed to tBid, of specific fatty acid metabolites able to act as endogenous stress signals on mitochondria, thus becoming integral participants in the apoptotic pathway.

To gain further insight into the mechanism of the effect of tBid on fatty acid metabolism in the present study, we applied permeabilized cell techniques to assess mitochondrial function in the hepatocytes after tBid, caspase inhibitors and exogenous cytochrome $c$ addition to the assay medium. Studying intact cells provides only limited information about mitochondrial function because it is difficult to control the extra mitochondrial medium and the mitochondrial functional state. ${ }^{8,9}$ Permeabilization of the plasma membrane for low molecular weight solutes allows the investigation of mitochondrial processes under precisely controlled conditions in situ, where mitochondrial interaction with intracellular structures is largely preserved. ${ }^{10}$

Early events of apoptosis that have been demonstrated in other cell systems have been reproduced herein. ${ }^{11,12}$ Specifically, we examined the temporal relationship between the loss of cytochrome $c$ and the loss of mitochondrial membrane potential after tBid addition to permeabilized cells. We confirmed that the tBid-induced release of cytochrome $c$ from mitochondrial intermembrane space can proceed in a caspase-independent manner, and that $\Delta \Psi_{\mathrm{m}}$ could be maintained, in the absence of caspase activation, by exogenous addition of cytochrome $c$. Although the apparent normality of mitochondrial functions in terms of metabolic capacity, measurement of several mitochondrial parameters related to fatty acid $\beta$-oxidation indicated that $\mathrm{tBid}$ caused $\beta$-oxidation inhibition via a blockade of the enzyme CPT-1 and an increase of palmitoyl-CoA. Furthermore, we demonstrated that the observed changes in CPT-1 activity were independent from malonyl-CoA, the key inhibitory molecule of CPT-1. Hence, a novel mechanism has to be involved in the tBid modulatory effect on CPT-1 activity, and is probably related to the capacity of tBid to affect the lipid composition of mitochondrial membranes. Indeed, our findings showed a decrease in cardiolipin level in mitochondria after tBid addition. This event, inducing a change in the lipid environment of mitochondrial membranes, may influence the activity of CPT-1 extremely sensitive to the lipid constituents of the microdomain in which it resides. ${ }^{13,14}$

To test whether the tBid-mediated effects on fatty acid metabolism and on CPT-1 activity requires proapoptotic members of the Bcl-2 family, such as Bax and Bak, suppression of gene expression by small interfering RNA (siRNA) was utilized to inhibit Bak and Bax expression in cultured cells. The results obtained have clearly demonstrated that their downregulation did not affect significantly the ability of tBid to reduce $\beta$-oxidation flux.
As Bcl-2 physically interacts with CPT-1 and tBid, ${ }^{15,16}$ we next examined whether the $\mathrm{Bcl}-2$ overexpression prevented the effect of tBid on CPT-1 activity. Interestingly, Bcl-2overexpressing cells showed a normal pattern of fatty acid $\beta$-oxidation also in the presence of tBid. Thus, $\mathrm{Bcl}-2$ antagonizes both the proapoptotic activity and the metabolic inhibitory capacity of tBid. On the other hand, tBid was not able to create complexes with CPT-1 as demonstrated by coimmunoprecipitation assay. Therefore, the CPT-1 inhibition mediated by tBid is most likely a result of an indirect rather than a direct effect of the proapoptotic factor on the enzyme.

Irrespective to the theoretical possibilities resulting from our experiments, it appears clear that (1) tBid, inhibiting $\beta$-oxidation flux, can induce the generation of potentially toxic fatty acid metabolites, such as palmitoyl-CoA, able to act as endogenous stress signals on mitochondria, ${ }^{17,18}$ and that (2) tBid-induced metabolic alterations can be prevented by $\mathrm{Bcl}-2$ overexpression.

Thus, for the first time we have shown that during apoptosis induced by tBid, mitochondria experience a progressive dysfunction that involves not only glucose metabolism, as already demonstrated, but also $\beta$-oxidation flux of long-chain fatty acid, and that compels the cell to the 'point-of-no-return' of the death program.

\section{Results}

\section{Inhibition of tBid-dependent mitochondrial membrane potential decrease by caspase inhibitors and cytochrome $c$ in permeabilized hepatocytes}

The activation of Bid and its translocation as tBid to mitochondrial membranes, attracted by the mitochondrionspecific lipid cardiolipin, is critical in the induction of apoptosis in certain types of cells such as hepatocytes. ${ }^{19}$ However, in the absence of the downstream caspase activities after cytochrome $c$ release, Bid seems to be not able to affect both cell viability and mitochondrial functional integrity. ${ }^{20}$

For the purposes of further studying the contribution of tBid in the regulation of mitochondrial function, we used permeabilized hepatocytes where the time-consuming and potentially damaging mitochondrial purification process was not necessary. In fact, the aim of the permeabilization procedure was to allow access of tBid and, where requested, cytochrome $c$ to the mitochondrial compartment while preserving intact mitochondria. Moreover this model has the advantage of preserving mitochondria in their normal intracellular location relative to other organelles and cytoskeleton proteins, and of being available for study within seconds of disrupting the plasma membrane. The degree of permeabilization was assessed by evaluating the release of marker enzymes from the cytosol (lactate dehydrogenase) and mitochondrial matrix (citrate synthase). About $80 \%$ of lactate dehydrogenase was released in the supernatant with digitonin at $40 \mu \mathrm{g} / \mathrm{ml}$, while $95 \%$ of the cells became permeable to Trypan blue (Figure 1). This digitonin concentration did not produce mitochondrial permeabilization, since all citrate synthase activity remained in the pellet, thus indicating that the mitochondria were intact (Figure 1). 


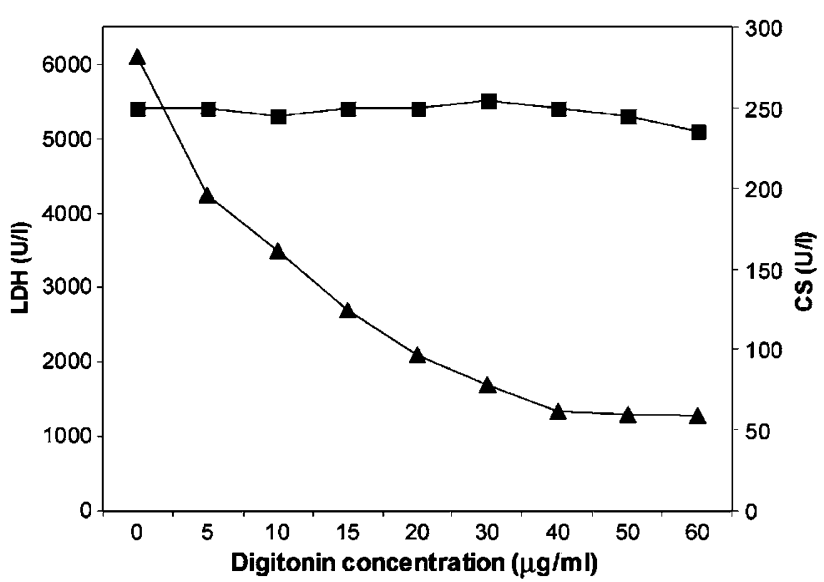

Figure 1 Release of lactate dehydrogenase and citrate synthase during digitonin permeabilization of hepatocytes. Cells were suspended in a buffer containing $220 \mathrm{mM}$ mannitol, $68 \mathrm{mM}$ sucrose, $10 \mathrm{mM}$ Hepes (pH 7.4), $70 \mathrm{mM}$ $\mathrm{KCl}, 1 \mathrm{mM}$ EGTA, $1 \mathrm{mM}$ PMSF and $2 \mu \mathrm{M}$ aprotinin. The experiments were carried out to choose the minimum amount of digitonin capable of selectively permeabilizing the plasma membrane within 5 min without affecting mitochondrial integrity. Lactate dehydrogenase $(\boldsymbol{\Delta})$ and citrate synthase $(\boldsymbol{\square})$ activities were measured in the cell pellet after washing with PBS

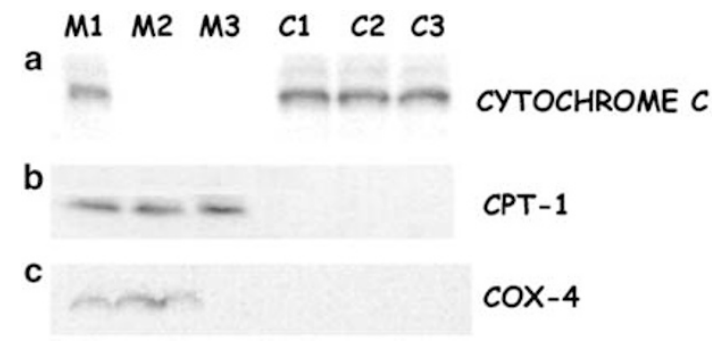

Figure 2 Outer membrane permeability and loss of cytochrome $c$ in mitochondria from digitonin-permeabilized hepatocytes treated with tBid. (a) The mitochondrial pellet $(\mathrm{M})$ and cytosolic fractions $(\mathrm{C})$ from hepatocytes after $30 \mathrm{~min}$ incubation at $37^{\circ} \mathrm{C} \mathrm{w} / \mathrm{wo} \mathrm{tBid}(20 \mathrm{ng} / \mathrm{ml})$, in the presence or absence of zVAD-fmk (zVAD; $100 \mu \mathrm{M})$, were probed with cytochrome $c$ antibody ( $\sim 15 \mathrm{kDa}$ ). (b) CPT-1 levels in mitochondria from digitonin-permeabilized hepatocytes treated or untreated with tBid. The experiment was performed as in panel a, except that the fractions were probed with CPT-1 antibody ( $\sim 88 \mathrm{kDa})$. (c) Mitochondrial and cytosolic fractions from treated or untreated cells probed with COX4 Antibody ( $\sim 17 \mathrm{kDa})$. M: mitochondrial fraction - M1: control; M2: tBid; M3: tBid + zVAD; C: cytosolic fraction - C1: control; C2: tBid; C3: tBid + zVAD

To ascertain whether the mitochondria from hepatocytes treated with tBid had depleted cytochrome $c$ independently of caspase activation, we isolated mitochondria from permeabilized cells, and assessed the amount of cytochrome $c$ in the mitochondrial pellet $(\mathrm{M})$ and supernatant $(\mathrm{C})$ fractions. Nearly all of the cytochrome $c$ was released from mitochondria isolated from the cells following tBid addition to the incubation mixture both in the presence or in the absence of $N$ benzyloxycarbonyl-Val-Ala-Asp-fluoromethyl ketone (zVAD$\mathrm{fmk}$ ), a general caspase inhibitor (Figure 2a).

Then, we determined whether tBid could induce loss of $\Delta \Psi_{\mathrm{m}}$ in permeabilized cells, in the presence or in the absence of exogenous cytochrome $c$ added to the incubation mixture. Consistent with previous results, addition of cytochrome $c$ restored $\Delta \Psi_{\mathrm{m}}$ in ZVAD-fmk- and tBid-treated

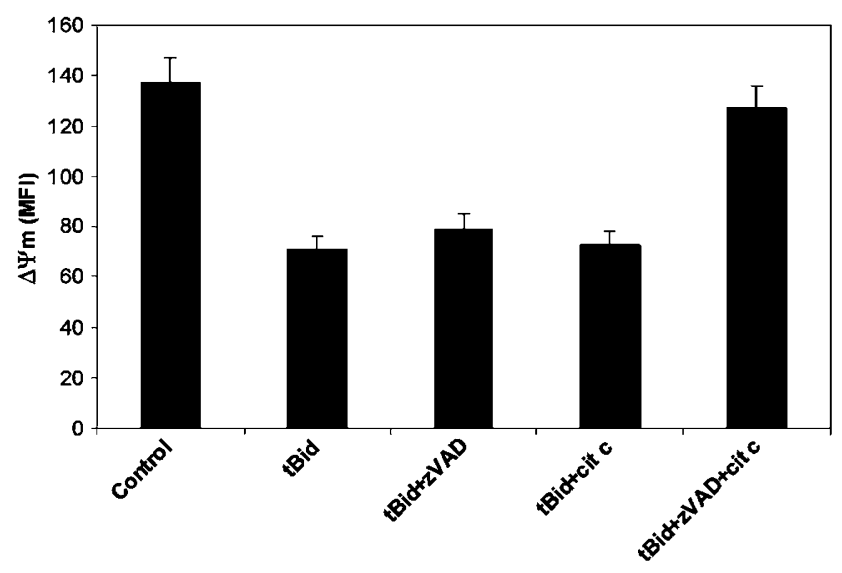

Figure 3 Cytochrome $c$ restores $\Delta \Psi_{\mathrm{m}}$ after tBid addition only in the presence of caspase inhibitor. Permeabilized hepatocytes $\left(10^{6}\right)$ were incubated with or without tBid $(20 \mathrm{ng} / \mathrm{ml})$, in the presence or absence of zVAD-fmk (zVAD; $100 \mu \mathrm{M})$ and/or cytochrome $c$ (cit c; $100 \mu \mathrm{M}$ ) plus TMRE at $37^{\circ} \mathrm{C}$ for 30 min with succinate as substrate. Cells were analyzed for $\Delta \Psi_{\mathrm{m}}$ by flow cytometry; the mean fluorescence intensity (MFI) values for cells treated with FCCP (trifluorocarbonylcyanide phenylhydrazone) to dissipate $\Delta \Psi_{\mathrm{m}}$ was set as 0

cells, while in the absence of anticaspase inhibitor, tBid induced a loss of $\Delta \Psi_{\mathrm{m}}$, which was not restored by cytochrome $c$ addition (Figure 3 ).

These data strongly support the conclusion that caspase functions were required for the onset of apoptotic events and of mitochondrial dysfunction as depicted by the dramatically $\Delta \Psi_{\mathrm{m}}$ decrease upon caspase activation. Without caspase activation, most mitochondria appeared to remain functional after the permeabilization of the outer mitochondrial membrane if cytochrome $c$ was exogenously added to the incubation mixture.

\section{Inhibition of fatty acid oxidation in hepatocytes by tBid}

The activation of the proapoptotic Bcl-2 members, such as Bid, in the presence of caspase inhibitors can permeabilize the mitochondrial outer membrane without disrupting $\Delta \Psi_{\mathrm{m}}$. Since mitochondrial functions including protein import, ATP generation, and lipid biogenesis depend on the maintenance of $\Delta \Psi_{\mathrm{m}}$, it is likely that tBid does not affect the mitochondrial metabolic activity if cytochrome $c$ is sufficiently available in the cell microenvironment. ${ }^{21}$

To evaluate whether the translocation of tBid to the mitochondria might induce changes in fatty acid oxidation, we treated hepatocytes with tBid in the presence of the caspase inhibitor, zVAD-fmk, and cytochrome $c$.

At first, we examined in our system the rate of $\beta$-oxidation flux of labeled palmitate, calculated as total acid-soluble radioactivity, as ${ }^{14} \mathrm{CO}_{2}$ release, or as total ${ }^{14} \mathrm{C}$-labeled products (i.e. the sum of acid-soluble radioactivity and of ${ }^{14} \mathrm{CO}_{2}$ release). Since the permeabilization process led to an increased availability of palmitate and carnitine to the mitochondria, a high production of acid-soluble radioactive metabolites was demonstrated in permeabilized untreated hepatocytes after palmitate addition (Figure 4). The accumulation of these 
metabolites was linear for at least $90 \mathrm{~min}$. We also evaluated the contribution of peroxisomal $\beta$-oxidation in our experiments. The data present in Figure 4 clearly demonstrates that the oxidation of substrate was significantly inhibited by the presence of inhibitors of the respiratory chain. Thus, the contribution of peroxisomes to the oxidation of palmitate under our experimental conditions is minimal, since peroxisomal activity is independent of the respiratory chain. After treatment with $\mathrm{tBid}$, the rate of oxidation of palmitate slowed down during the initial $30 \mathrm{~min}$ (Figure 5). The maximum difference in oxidation rate between treated and untreated hepatocytes was reached after $1 \mathrm{~h}$ (three-fold difference). Figure 5 also shows that the oxidation of octanoate is not depressed at all by tBid treatment. It is well known that octanoate, a medium-chain fatty acid, is transported into the mitochondria independently of carnitine, while palmitate, a

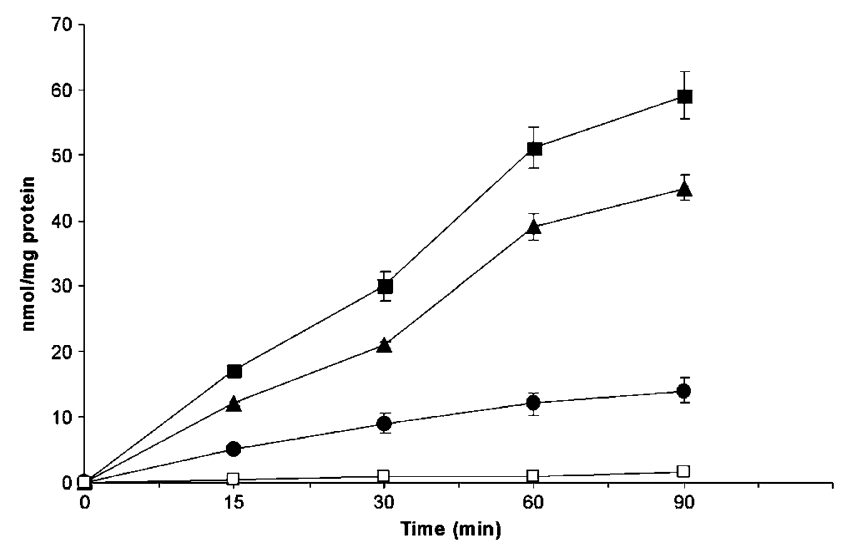

Figure $4 \quad \beta$-Oxidation flux in permeabilized hepatocytes. Incubations were performed and products analyzed as described in the 'Materials and Methods' section. Results are means \pm S.D. for three to five incubations. Symbols: $\mathbf{\square}$, total ${ }^{14} \mathrm{C}$-labeled products; $\boldsymbol{\Delta}$, total acid-soluble radioactivity; $\boldsymbol{O},{ }^{14} \mathrm{CO}_{2}$ release; $\square$, total ${ }^{14} \mathrm{C}$-labeled products in the presence of a mixture of rotenone $(5 \mathrm{mg} / \mathrm{l})$, antimycin $A(5 \mathrm{mg} / \mathrm{l})$ and sodium cyanide $(1 \mathrm{mM})$

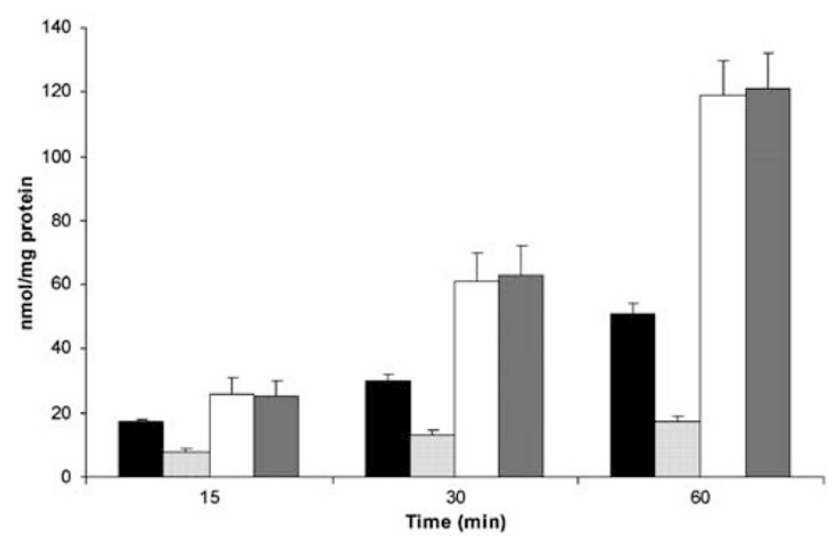

Figure 5 tBid-mediated inhibition of $\beta$-oxidation flux in hepatocytes. Hepatocytes were incubated with $\left[1-{ }^{14} \mathrm{C}\right]$ palmitate or $\left[1-{ }^{14} \mathrm{C}\right]$ octanoate in the presence or absence of tBid ( $20 \mathrm{ng} / \mathrm{ml})$ plus zVAD-fmk $(100 \mu \mathrm{M})$ and cytochrome $c(100 \mu \mathrm{M})$ at the indicated times. Total ${ }^{14} \mathrm{C}$-labeled products were measured as described in the 'Materials and Methods' section. Values are means \pm S.D. from three parallel experiments. Symbols: $\square$, palmitate; $\square$, palmitate + tBid; $\square$, octonoate; $\square$, octonoate + tBid long-chain fatty acid, is imported into the mitochondria by a carnitine-dependent transport. Thus, the results obtained may indicate that the tBid treatment depresses fatty acid oxidation by means of the downregulation of carnitine-dependent transport of fatty acid into mitochondria.

To determine whether tBid also influenced pyruvate flux through pyruvate dehydrogenase $(\mathrm{PDH})$, permeabilized cells were incubated in the presence of labeled pyruvate, and its conversion into ${ }^{14} \mathrm{CO}_{2}$ was analyzed. These experiments showed that tBid caused an increase in ${ }^{14} \mathrm{CO}_{2}$ production rather than a decrease when the cells were incubated with pyruvate (331.5 versus $391.1 \mathrm{nmol} \quad \mathrm{CO}_{2} /$ $30 \mathrm{~min} / \mathrm{mg}$ protein released from control and tBid-treated cells, respectively).

\section{$\beta$-Oxidation intermediate profiles in tBid-treated cells}

To verify the possibility that a deficiency of the mitochondrial carnitine system might occur following tBid treatment, we analyzed the pattern of $\beta$-oxidation intermediates in cells incubated in the presence of labeled palmitate. To select the incubation time for determining the pattern of intermediates, we carried out preliminarily a time-course incubation and analyzed the acyl-CoA and acylcarnitine esters generated. Preliminary results showed that, under the experimental conditions applied, a typical intermediate profile is achieved rapidly and maintained for up to $2 \mathrm{~h}$. Thus, an incubation time of $60 \mathrm{~min}$ was chosen and used throughout the rest of the study. In permeabilized control cells, only traces of palmitoylCoA esters could be detected, while acylcarnitine esters were easily identified, showing a typical pattern of intermediates. In particular, acetylcarnitine and palmitoyl-carnitine were the main carnitine esters detected in control cells. The other intermediates were present only in traces and are not reported in Table 1. In tBid-treated cells, the absolute amount of palmitoyl-CoA detected was four times the average amount of palmitoyl-CoA detected in the control cells. On the other hand, it was not possible to identify or quantify most of acylcarnitines intermediates. Only acetylcarnitine production was detectable at low level. The results of quantitative palmitoyl-CoA and acylcarnitine profiles accumulating in the reaction mixture after tBid treatment compared with controls were summarized in Table 1.

Taken together, these findings provide further corroboration of the puzzling observation that tBid induces alterations of the mitochondrial carnitine-dependent transport of fatty acids.

Table 1 Amount of ${ }^{14} \mathrm{C}$-labeled palmitoyl-CoA, acetylcarnitine and palmitoylcarnitine generated during the oxidation of $\left[\mathrm{U}-{ }^{14} \mathrm{C}\right]$ palmitate by hepatocytes in the presence or in the absence of $\mathrm{tBid}(20 \mu \mathrm{g} / \mathrm{ml})$, cytochrome $c(100 \mu \mathrm{M})$ and zVAD-fmk $(100 \mu \mathrm{M})$

\begin{tabular}{lcc}
\hline & Control & tBid \\
\hline Palmitoyl-CoA (pmol/h/mg protein) & $10 \pm 1$ & $43 \pm 1$ \\
Acetylcarnitine (nmol/h/mg protein) & $33.7 \pm 7$ & $15.9 \pm 3$ \\
Palmitoylcarnitine (nmol/h/mg protein) & $1.45 \pm 0.6$ & $0.4 \pm 0.1$
\end{tabular}




\section{tBid inhibition of CPT-1: the role of malonyl-CoA}

One possible target for tBid action might be CPT-1, the enzyme involved in the synthesis of palmitoyl-carnitine from activated palmitate. CPT-1 catalyzes the pace-setting step of long-chain fatty acid import into the mitochondrial matrix. The other components of the carnitine system, namely carnitine/ acylcarnitine translocase and carnitine palmitoyltransferase-2 (CPT-2), are generally not considered to play a significant regulatory role in the translocation of long-chain fatty acid into the mitochondrial matrix.

An assay was performed to test CPT-1 activity on permeabilized primary human hepatocytes to further evaluate the mechanism underpinning the observation that tBid addition to cells influenced mitochondrial fatty acid $\beta$-oxidation flux. As shown in Figure 6, CPT-1 activity was decreased by exposure of permeabilized hepatocytes to tBid, thus demonstrating a correlation between decreased enzyme activity and diminished palmitate utilization. To exclude enzyme degradation and/or leakage at the outer mitochondrial membrane, a quantitative analysis of CPT-1 was carried out on isolated mitochondria by immunoblotting. No evidence of variations in the amount of mitochondrial CPT-1 was demonstrated (Figure 2b).

Since it has been shown that CPT-1 is reversibly inhibited by malonyl-CoA, it was conceivable that tBid-induced inhibition of long-chain fatty acid oxidation was mediated by an increased intracellular malonyl-CoA level. On the other hand, because the permeabilization process of the hepatocytes led to a substantial dilution of cytosolic components including malonyl-CoA, it was unlikely that the intracellular level of malonyl-CoA could reach a value capable of inhibiting CPT-1 activity.

To understand whether the mechanism involved in the tBidinduced inhibition of CPT-1 was malonyl-CoA dependent or independent, enzyme activity was determined by a procedure that eliminated any possible interference of malonyl-CoA. In

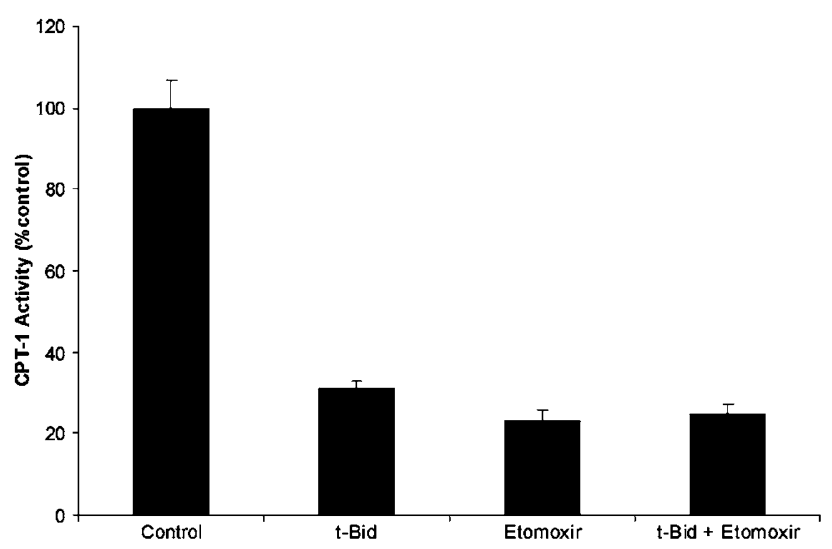

Figure 6 Inhibitory effect of tBid on CPT-1 activity in permeabilized hepatocytes. Digitonin-permeabilized cells were preincubated for $30 \mathrm{~min}$ in the absence or in the presence of tBid $(20 \mathrm{ng} / \mathrm{ml})$ plus zVAD-fmk $(100 \mu \mathrm{M})$ and cytochrome $c(100 \mu \mathrm{M})$. Palmitoyl-carnitine formation from labeled L-carnitine and palmitoyl-COA was measured after cell incubation for $5 \mathrm{~min}$ with or without etomoxir $(100 \mu \mathrm{mol} / \mathrm{l})$, an irreversible CPT-1 inhibitor. Results correspond to seven different hepatocytes preparations and are given as means \pm S.D. Significantly different versus incubations with no additions: $P<0.01$ such an assay, permeabilized cells, once treated with tBid, were extensively washed to achieve complete removal of malonyl-CoA. Determination of the enzyme activity was then performed after a lag period of $15 \mathrm{~min}$, so that any conformational constraint of CPT-1, due to previous binding with malonyl-CoA, disappeared. Finally, the malonyl-CoA level was evaluated in parallel cultures undergone the same procedure.

The use of this method confirmed that the inhibition of CPT1 by tBid treatment is exerted by a malonyl-CoA-independent mechanism. Indeed, no detectable amounts of malonyl-CoA were found in cells processed as described. In this respect, it is noteworthy that the negative effect of tBid on the catalytic efficiency of CPT-1 was identical to that in the previous experiments.

\section{tBid affects the cardiolipin levels in mitochondrial membranes}

Previous results have shown that the outer membrane CPT-1 and the inner membrane CACT and CPT-2 are enriched in the mitochondrial contact sites, suggesting an organization within the contact site that facilitates the carnitine-dependent transport of fatty acyl groups across the mitochondrial membrane. Contact sites are purported to have a unique lipid environment that is rich in cardiolipin. This lipid is associated, probably with a regulatory function, with numerous mitochondrial transporters such as the adenine nucleotide translocator (ANT). Interestingly, recent papers have demonstrated both that the targeting of tBid to mitochondria depends upon the presence of the cardiolipin and that tBid localizes specifically to the mitochondrial contact sites rich in cardiolipin. ${ }^{22-24}$

To evaluate whether tBid was capable to modify the lipid composition of the mitochondrial membranes, thus affecting fatty acid import machinery, we analyzed the mitochondrial cardiolipin content by HPLC. The cardiolipin concentration was calculated in reference to internal standard, tetrastearoylcardiolipin, a synthetic analog uncommon in biological specimens. The method applied allowed a measure of cardiolipin concentration with a quantitation limit of $0.5 \mathrm{nmol}$. As depicted in Figure 7, exposure of mitochondria to tBid resulted in a decrease of cardiolipin level compared with untreated mitochondria.

\section{tBid-induced alterations of fatty acid metabolism do not require functions of the proapoptotic proteins Bax and Bak and are inhibited by $\mathrm{Bcl}-2$}

Well-known mediators of mitochondria damage include the proapoptosis members of the Bcl-2 family, Bax and Bak, which may self-oligomerize in mitochondria outer membrane to permeabilize it. ${ }^{25}$ In a mouse model, knockout of both Bax and Bak conferred resistance to normal apoptosis in animal development and in experimental apoptosis induced by many apoptosis-inducing agents. ${ }^{26}$

Thus, the ability of Bak and Bax to act as agonist of tBid in inducing modifications of mitochondrial fatty acid flux was also investigated by using siRNA-mediated knockdown. Hepatocytes were transfected either with a control siRNA (a random 


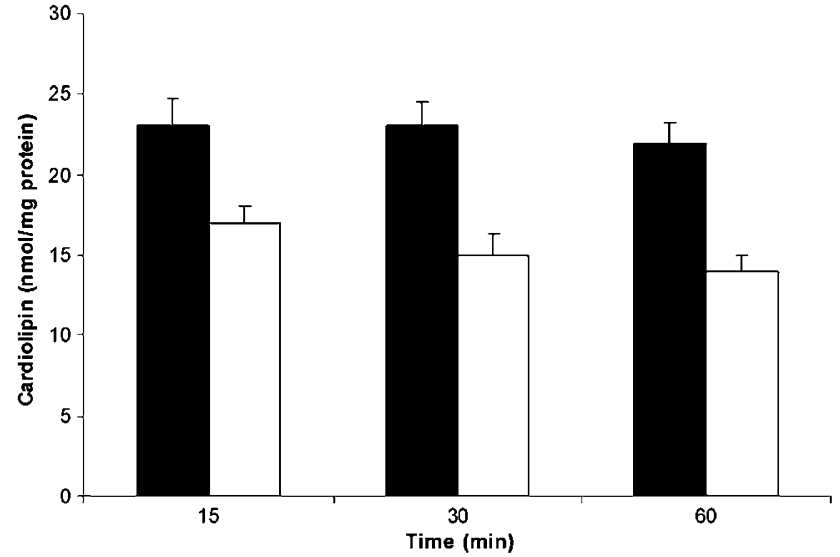

Figure 7 Loss in the cardiolipin content in mitochondria of hepatocytes incubated with tBid. Hepatocytes were incubated at $37^{\circ} \mathrm{C}$ for different times in the absence (control) $(\boldsymbol{\square})$ or presence $(\square)$ of tBid $(20 \mathrm{ng} / \mathrm{ml})$ plus zVAD-fmk $(100 \mu \mathrm{M})$ and cytochrome $c(100 \mu \mathrm{M})$. Cardiolipin content was determined as described in 'Materials and Methods'. All values are expressed as mean \pm S.D. of five separate experiments

scrambled sequence; si-Scr) or with gene-specific siRNAs targeted against Bax (si-Bax), and/ or Bak (si-Bak). Cells were analyzed at 48 and $72 \mathrm{~h}$ post-transfection for protein expression by immunoblotting (Figure 8 ). While both si-Bax and siBak inhibited specific protein expression, si-Scr had no significant effect on expression of Bax or Bak. si-Bax downregulated Bax, but no such effect was observed on expression of either Bcl-2 or Bak. Similarly, si-Bak was specific for Bak as no downregulation of Bax, or Bcl-2 proteins was observed.

Since siRNA has been shown to result in interferon (IFN) gene induction in some cells, ${ }^{27}$ transfected cells were also analyzed for two different IFN-stimulated genes (ISGs), signal transducer and activator of transcription 1 (STAT-1) and ISG15 (p15). ${ }^{28}$ Compared to controls, the gene-specific siRNAs utilized in this study did not induce STAT-1 or ISG15 protein expression in the cells (data not shown).

Knockdown of Bax or Bak did not affect the ability of tBid to modulate negatively the mitochondrial $\beta$-oxidation capacity via CPT-1 inhibition, suggesting that this effect of tBid is not dependent on Bax or Bak alone. Also when both Bax and Bak were subjected to knockdown, the capacity of tBid to induce CPT-1 inhibition was not decreased (Figure 8).

We next determined whether the Bcl-2 overexpression prevented the effect of tBid on lipid metabolism. Interestingly, Bcl-2-overexpressing cells showed a normal pattern of fatty acid $\beta$-oxidation and CPT-1 activity also in the presence of tBid (Figure 9). Together, these results suggest that, in addition to preventing the apoptotic pathway, Bcl-2 may antagonize tBid-induced metabolic dysfunctions of mitochondria.

\section{tBid does not co-immunoprecipitate with CPT-1}

Our results suggested that after insertion into mitochondrial membranes tBid inhibited CPT-1 activity. One hypothesis about the underlying mechanism was that tBid might directly interact with CPT-1, resulting in conformational changes in
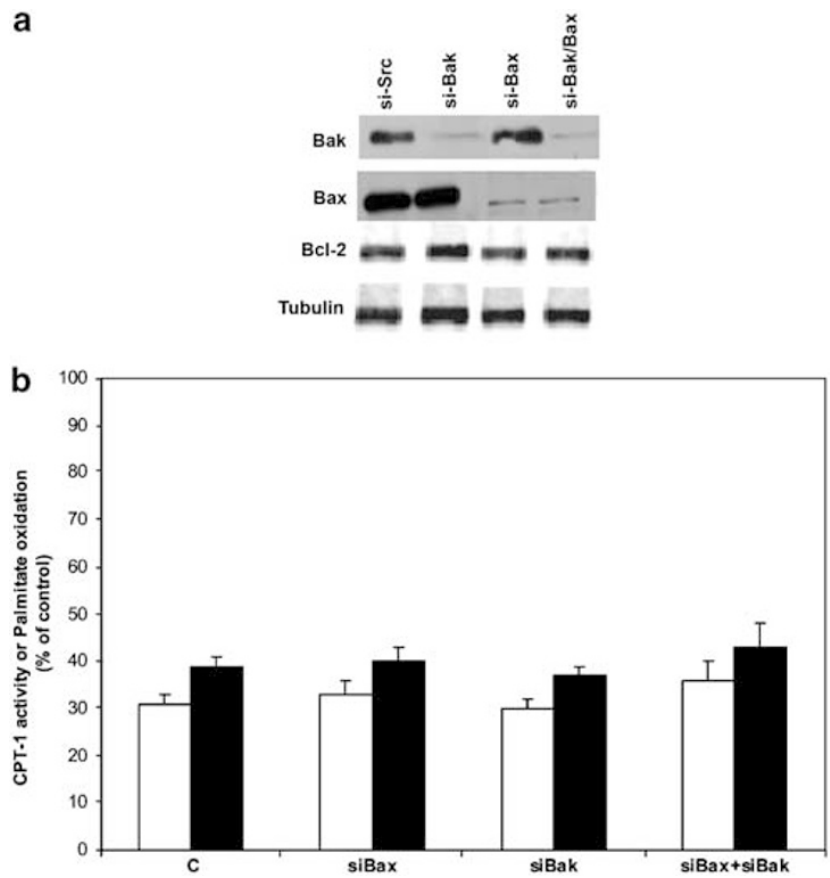

Figure 8 Suppression of Bax and/or Bak gene expression by specific si-RNAs fails to inhibit the effects of tBid on CPT- 1 activity and $\beta$-oxidation flux. (a) Genespecific si-RNAs (si-Bak and/or si-Bax) or the control si-RNAs (si-Src) were added to the media using lipophilic transfection-enhancing reagent. Cells were harvested after $48 \mathrm{~h}$ and immunoblot analyses were performed using Bcl-2-, Baxand Bak-specific antibodies. The blots were reprobed with antibody against tubulin to confirm equal protein loading. Control si-RNAs had no effect; however, Bax and Bak si-RNAs effectively inhibited expression of the specific genes by $>93 \%$ (three independent experiments). No downregulation of $\mathrm{Bcl}-2$ expression was observed. (b) Control cells $(C)$ and cells transfected with Bax and/or Bak siRNAs were permeabilized and preincubated for $30 \mathrm{~min}$ in the presence of tBid $(20 \mathrm{ng} / \mathrm{ml})$ plus zVAD-fmk $(100 \mu \mathrm{M})$ and cytochrome $c(100 \mu \mathrm{M})$. Subsequently, the rate of CPT-1 activity $(\square)$ as well as palmitate oxidation $(\boldsymbol{\square})$ was determined (see Materials and Methods). The values are expressed as the percentage of the controls without tBid. Results correspond to seven different hepatocytes preparations and are given as means \pm S.D.

this molecule that prevented its enzymatic catalysis. To test this possibility, we examined the interactions between CPT-1 and tBid by co-immunoprecipitation. In this experiment, cells extracts were subjected to immunoprecipitation with CPT-1 antibodies. The immunoprecipitates were analyzed for the presence of tBid. As shown in the Figure 10, tBid was not shown in any of the CPT-1 immunoprecipitates. To demonstrate that the extracts prior to immunoprecipitation did contain tBid, we analyzed the extracts directly by immunoblotting (Figure 10). Clearly, the results suggest that CPT-1 did not co-immunoprecipitate $15-\mathrm{kDa}$ tBid under the experimental conditions applied, although membranous insert of tBid was present.

\section{Discussion}

As mitochondria are major players in the cell death decision and in cellular energy metabolism, it is not surprising that proapoptotic factors, such as tBid, interacting with the mitochondria can produce changes in the cellular metabolism. 

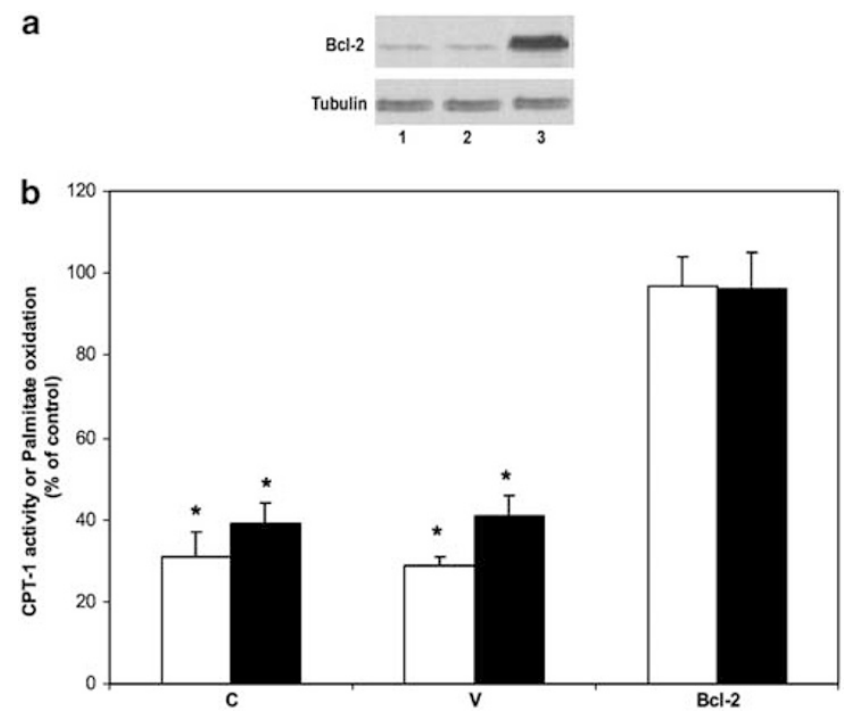

Figure 9 Effects of Bcl-2 overexpression on tBid-induced metabolic alterations. (a) Western blot analysis of Bcl-2 and tubulin expression in control cells (1), in empty vector-transfected cells (2) and in Bcl-2-transfected cells (3). (b) Control cells $(\mathrm{C})$ and cells transfected with empty vector $(\mathrm{V})$ or $\mathrm{Bcl}-2$ (Bcl-2) were analyzed for CPT-1 activity $(\square)$ and palmitate oxidation ( $\mathbf{})$ in the presence of tBid $(20 \mathrm{ng} / \mathrm{ml})$ plus ZVAD-fmk $(100 \mu \mathrm{M})$ and cytochrome $c(100 \mu \mathrm{M})$ (see Materials and Methods). The values are expressed as the percentage of the controls without tBid. Results correspond to seven different hepatocytes preparations and are given as means \pm S.D. ${ }^{*} P<0.01$

a
IB: anti-tBid

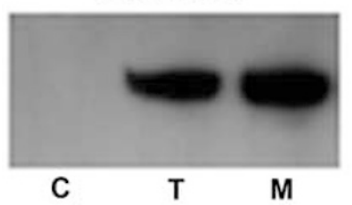

b IP: anti-CPT-1
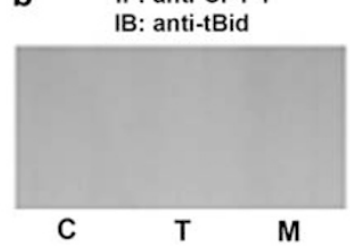

Figure 10 Co-immunoprecipitation analysis of CPT-1 and tBid. Hepatocytes were permeabilized, subjected $(\mathrm{T})$ or not $(\mathrm{C})$ to tBid treatment (see Materials and Methods), and then mitochondria were isolated and incubated with $10 \mathrm{mM} \mathrm{BMH}$ crosslinker. The mitochondrial pellets were lysed in RIPA buffer. The extracts were directly used for immunoblot analysis of tBid (IB), or subjected to immunoprecipitation (IP) with anti-CPT-1 antibody followed by detection of tBid in the precipitates by immunoblotting. In another set of experiments, mitochondria (M) were isolated from hepatocytes, incubated with tBid, and then treated with $10 \mathrm{mM} \mathrm{BMH}$. Immunoprecipitation (with anti-CPT-1 antibody) and/or immunoblotting (with anti-tBid antibody) were performed as described before. (a) tBid was detected in RIPA extracts prior to immunoprecipitation. In the absence of tBid treatment, no detection was demonstrated (lane C). (b) tBid was not shown in any of the precipitates obtained using anti-CPT-1 antibody

In particular, the modulation of lipid oxidation flux by tBid in apoptotic cells deserves more attention not only because mitochondria are a crossroad of the cell lipid trafficking but also because the accumulation of specific fatty acids metabolites may amplify or/and contribute to the apoptotic process.

Indeed, although lipids are often forgotten in the common schemes of apoptosis, they appear to be involved (a) in cell death receptor clustering, (b) in mediating stress-induced apoptosis and/or amplifying cell death signal transduction pathways, (c) in the mitochondrial alterations that accompany apoptosis, or (d) in apoptotic cell recognition and engulfment. ${ }^{29}$ This has even led to the proposal of a lipid biostat, which modulates apoptosis induction. In addition, some fatty acids or fatty acid metabolites modulate cell growth and induce apoptosis, some of them displaying properties of potential antitumorigenic compounds. ${ }^{30,31}$

Recent papers suggest an intriguing connection between the accumulation and/or abnormal metabolism of fatty acids and the apoptosis-associated dysfunction of mitochondria. Saturated long-chain fatty acids, such as palmitate, and their cognate CoA-derivatives have been reported to induce mitochondrial membrane permeability transition, to bind to the ANT, to uncouple the respiratory chain and to determine cytochrome $c$ release. ${ }^{18,32}$ Moreover, it has been reported that palmitoyl-CoA is a precursor of de novo synthesis of ceramide, a sphingolipid metabolite important as intracellular mediator of programmed cell death. ${ }^{33}$ The generation of the proapoptotic second messenger ceramide is stimulated by inhibition of CPT-1, an enzyme that resides at the outer mitochondrial membrane and catalyzes the synthesis of palmitoylcarnitine from palmitoyl-CoA. ${ }^{6}$ CPT-1 together with carnitine/acylcarnitine translocase and CPT-2 regulates the import of long-chain fatty acids into the mitochondrial matrix for $\beta$-oxidation. CPT-1 catalyzes the rate-limiting step in this passage and is site for intracellular regulation of fatty acid metabolism, with malonyl-CoA acting as a physiological inhibitor. ${ }^{34,35}$ Other studies found a physical association between CPT-1 and $\mathrm{Bcl}-2$ on the outer mitochondrial membrane providing an additional potential link between CPT-1 and the regulation of apoptosis. ${ }^{15}$

Intrigued by these observations, we have explored the rate of $\beta$-oxidation as well as the intermediates of $\beta$-oxidation and CPT-1 activity in hepatocytes treated with the activated $\mathrm{BH} 3-$ only protein, tBid. To carry out this experimental design, we developed a procedure for measuring lipid metabolism and CPT-1 activity in digitonin-permeabilized hepatocytes in the presence of caspase inhibitors and exogenous cytochrome $c$. Although tBid causes a rapid release of cytochrome $c$, it does not disrupt significantly $\Delta \Psi_{\mathrm{m}}$ when caspase activity is inhibited. This effect requires a readdition of exogenous cytochrome $c$ into the incubation mixture to restore the depleted cytochrome $c$ stores. Since mitochondrial functions including protein import, ATP generation, and lipid metabolism depend on the maintenance of $\Delta \Psi \mathrm{m}$, it seems that tBid alone is not able to induce mitochondrial dysfunction. On the contrary, measurement of several mitochondrial parameters related to fatty acid $\beta$-oxidation indicated that $\mathrm{tBid}$ caused $\beta$-oxidation inhibition, probably reflecting a blockade of the enzyme carnitine palmitoyl-transferase-1. To test this hypothesis, we used a method for measuring CPT-1 activity in the permeabilized cells. The use of such procedure showed that incubations of hepatocytes with tBid did change CPT-1 activity coordinately with the rate of $\beta$-oxidation. Furthermore, we demonstrated that malonyl-CoA, a key inhibitory molecule of CPT-1, was leaked completely out of the permeabilized hepatocytes, demonstrating that a malonyl-CoA was not responsible for the observed changes in CPT-1 activity. Normally, CPT-1 is regulated by at least three mechanisms: (a) variation in enzyme activity assumed to be due to enzyme 
synthesis or breakdown; (b) a variable level of malonyl-CoA; and (c) a sensitivity of the enzyme to the composition of the microdomain in which it resides. Usually, the rate of fatty acid $\beta$-oxidation is correlated with changes in malonyl-CoA concentration. Only in few cases it has been demonstrated to vary with a malonyl-CoA-independent mechanism. ${ }^{36}$ In the present study, we have shown that fatty acid $\beta$-oxidation and CPT-1 activity in permeabilized hepatocytes treated with tBid revealed significant changes that are independent of changes in malonyl-CoA levels, and that are too fast to involve enzyme synthesis. Hence, a novel mechanism, probably related to a modified composition of the mitochondrial membrane, has to be involved in the tBid modulatory effect of CPT-1 activity. Traditionally, mitochondrial membranes have been considered static, at least from a biochemical point of view, both in physiological and pathological conditions. This notion has completely changed during the last few years, just for the studies on tBid.

It has been demonstrated that the targeting of the proapoptotic protein tBid to mitochondria depends upon the presence of the mitochondria-specific lipid cardiolipin, which has a specific distribution pattern within mitochondria. ${ }^{37,38}$ Cardiolipin is found at high concentrations throughout the inner mitochondrial membrane, including the contact sites between the inner and outer membrane. ${ }^{37}$ Immunogold tomography revealed that these contact sites are the preferential targets for association of tBid. ${ }^{39}$ Like other membrane-perturbing factors, tBid can alter the lipid composition of mitochondria membrane via its lipid transfer activity that can affect both cardiolipin synthesis, recycling or oxidation, and mitochondrial respiration. ${ }^{40,41}$ This would account for the progressive loss of mitochondrial cardiolipin that we found after the addition of tBid to permeabilized cells. The existence of a cause and effect relationship between these two events, cardiolipin loss and decrease of CPT-1 activity, is suggested by the peculiarity of the enzyme insertion in the mitochondrial membrane.

Interestingly, CPT-1 of liver mitochondria is an integral, polytopic protein of the outer membrane that is enriched at contact sites. ${ }^{42}$ This topology endows the protein with the potential for modifying the conformation of its catalytic C-domain in response to variations in the membrane environment. Indeed, CPT-1 kinetics are extremely sensitive to the molecular order of the constituent lipids of the membrane environment in which it resides. ${ }^{13,14}$ Thus, a possible mechanism for the changes observed in our model might be the altered interaction of CPT-1 with the tBidmodified mitochondrial membrane resulting in a protein conformational change able to affect specifically the acylCoA binding site. With respect to this, it is plausible that changes in membrane environment, because of the formation of localized membrane microdomains of distinctive lipid composition due to the action of tBid, would induce altered activity of CPT-1. ${ }^{14}$

Consistent with these observations, our experiments have shown that there is no physical interaction of CPT-1 and tBid as demonstrated by co-immunoprecipitation assay. Thus, the modulation of CPT-1 activity by tBid is most likely a result of an indirect rather than a direct effect of the molecule on the enzyme. Moreover, despite the recognized role for Bax/Bak in inducing loss of mitochondrial integrity, both factors did not show any agonist or antagonist effect on $\beta$-oxidation flux. Indeed, siRNA-mediated knockdown of both factors did not affect the ability of tBid to induce modifications on lipid metabolism, suggesting that this effect is mainly dependent on tBid alone. Interestingly, the only manipulations that effectively reduces the tBid-mediated mitochondrial dysfunction was transfection-enforced expression of $\mathrm{Bcl}-2$. In fact, results of the current study have shown that the overexpression of $\mathrm{Bcl}-2$ prevents the inhibition of $\beta$-oxidation in the hepatocytes treated with tBid. One mechanism whereby $\mathrm{Bcl}-2$ may directly inhibit tBid-mediated effects is through the formation of $\mathrm{Bcl}-2 / \mathrm{tBid}$ complexes. These complexes were described in case of cells undergoing tumor necrosis factor$\alpha$-induced apoptosis. ${ }^{43}$ Other studies suggest that $\mathrm{Bcl}-2$ is able to decrease significantly the tBid insertion and/or integration in the mitochondrial membranes, a condition that strongly decreases the proapoptotic capacity of tBid. ${ }^{16}$

Alternatively, Bcl-2 may antagonize the action of tBid by interacting directly with CPT-1. Such interaction has been reported in various kinds of experimental models ${ }^{15}$ and may inhibit the conformational changes in CPT-1 induced by tBid, thus preserving both enzymatic activity and mitochondrial $\beta$-oxidation flux.

Finally, the impaired CPT- 1 activity could account for the increase of palmitoyl-CoA that we have demonstrated in tBidtreated cells. This increase can explain because mitochondria experience a progressive dysfunction in presence of tBid and without caspase activation. In fact, palmitoyl-CoA induces directly mitochondrial swelling and depolarization, thereby enhancing the irreversible mitochondrial alterations. Moreover, an accumulation of palmitoyl-CoA as a result of CPT-1 inhibition can influence the synthesis of ceramide, a molecule that play an important role in inducing programmed cell death. Thus, the alteration of mitochondrial fatty acid oxidation flux in apoptotic cells is a regulatory event of the cell death process rather than a by-product of apoptosis. This hypothesis suggests the existence of a system of lipid instructions that directly or indirectly, via the modulation of the killing activity of proapoptotic proteins, conditions the 'decision to die'.

\section{Materials and Methods}

\section{Cell culture and chemicals}

Primary human hepatocytes, culture reagents and media were purchased from Clonetics, (East Rutherford, NJ, USA). [U- $\left.{ }^{14} \mathrm{C}\right]$ Palmitate, $\left[\mathrm{U}-{ }^{14} \mathrm{C}\right]$ octanoate, $\left[1-{ }^{14} \mathrm{C}\right]$ pyruvate and $\mathrm{L}-\left[\right.$ methy $\left./-{ }^{14} \mathrm{C}\right]$ carnitine were obtained from Amersham Pharmacia Biotech (Milan, Italy). Digitonin and zVAD-fmk were purchased from Sigma (Milan, Italy). Human recombinant tBid in PBS ( $>95 \%$ purity) was purchased from Alexis Biochemicals (Vinci, Italy) and used at a concentration of $20 \mathrm{ng} / \mathrm{ml}$. In parallel, caspase8-cleaved recombinant human Bid (R\&D Systems, Milan, Italy) was used at a concentration of $30 \mathrm{ng} / \mathrm{ml}$. The purification of tBid from R\&D Systems did not employ detergent as depicted on the data sheet. No significant differences were seen between the two products on the ability to induce release of cytochrome $c$ in isolated mitochondria or to inhibit CPT-1 activity in permeabilized cells. All the experiments showed in the paper were performed using the product from Alexis Biochemicals. 


\section{Analysis of $\Delta \Psi_{m}$ in permeabilized primary hepatocyte cells}

Before permeabilization, hepatocytes were suspended in buffer $A$ containing $220 \mathrm{mM}$ mannitol, $68 \mathrm{mM}$ sucrose, $10 \mathrm{mM}$ Hepes (pH 7.4), $70 \mathrm{mM} \mathrm{KCl}, 1 \mathrm{mM}$ EGTA, $1 \mathrm{mM}$ phenyl methyl sulfonyl fluoride (PMSF) and $2 \mu \mathrm{M}$ aprotinin. Different amounts of digitonin were added to cell preparations for choosing the quantity of molecule able to permeabilize selectively the plasma membrane without affecting mitochondria integrity. Citrate synthase and lactate dehydrogenase activities were measured by standard procedures to evaluate the integrity of mitochondria and the effectiveness of cell permeabilization process. ${ }^{44,45}$

For $\Delta \Psi_{\mathrm{m}}$ analysis, permeabilized cells were incubated in the buffer $\mathrm{A}$ for $30 \mathrm{~min}$ at $37^{\circ} \mathrm{C}$ in the presence or absence of tBid $(20 \mathrm{ng} / \mathrm{ml})$, with or without cytochrome $c(100 \mu \mathrm{M})$, and/ or zVAD-fmk $(100 \mu \mathrm{M})$. Finally, the hepatocytes were incubated with $2 \mathrm{mM}$ ADP, $2 \mathrm{mM}$ DTT, $50 \mathrm{nM}$ tetramethylrhodamine ethyl ester (TMRE) and $5 \mathrm{mM}$ succinate and analyzed by flow cytometry on a FACScan (Becton Dickinson) measuring TMRE fluorescence in FL-2.

\section{Isolation of mitochondria and Western blot analysis for cytochrome $c$ release}

Mitochondria were isolated as described in detail previously. ${ }^{46}$. The isolation procedure was performed at $4^{\circ} \mathrm{C}$. Briefly, hepatocytes were resuspended in buffer $A$, incubated for $30 \mathrm{~min}$ in the presence or absence of tBid, and disrupted using a Dounce with a tight fitting Teflon pestle. Mitochondrial pellet $(\mathrm{P})$ and supernatant $(\mathrm{S})$ fractions were obtained by spinning the mixture at $8000 \times g$ for $5 \mathrm{~min}$. Hypotonically lysed mitochondria from untreated cells were used as positive controls; they were prepared as described previously. ${ }^{47}$ Cytochrome cimmunoblotting of the two fractions was performed with a commercially available anticytochrome $c$ monoclonal antibody (Pharmingen, Milan, Italy). The blots were visualized by the ECL method (Amersham Pharmacia Biotech, Milan, Italy). To confirm that mitochondrial fraction was successfully separated from the cytosolic fraction, both fractions were probed with cytochrome c oxidase polypeptide IV (COX4) antibody (R\&D Systems, Milan, Italy) by Western blot procedure.

\section{Measurement of fatty acid oxidation and analysis of acylcarnitine intermediates in tBid treated-hepatocytes}

Permeabilized hepatocytes were suspended in a buffer containing $110 \mathrm{mM} \mathrm{KCl}, 1 \mathrm{mM}$ EGTA, $5 \mathrm{mM} \mathrm{MgCl}$, $10 \mathrm{mM}$ potassium phosphate, $1 \mathrm{mM} \mathrm{ADP}$ and $10 \mathrm{mM} \mathrm{N}$-2-hydroxyethylpiperazine- $N$-2-ethanesulfonic acid with or without tBid for $30 \mathrm{~min}$ at $37^{\circ} \mathrm{C}$ in a shaking water bath $(150$ strokes/min). After this preincubation period, $5 \mathrm{mM} \mathrm{ATP}, 0.1 \mathrm{mM} \mathrm{CoA}$, $1 \mathrm{mM}$ L-carnitine, $100 \mu \mathrm{M}$ cytochrome $c$ and $50 \mu \mathrm{M}$ [U- ${ }^{14} \mathrm{C}$ ]palmitate, complexed to fatty acid-free albumin in a 5:1 molar ratio (specific radioactivity $50 \mathrm{Ci} / \mathrm{mol}$ ), were added. For the flux measurements, aliquots $(50 \mu l)$ were quenched at timed intervals with an equal volume of glacial acetic acid. Unreacted substrate was removed by the addition of fatty-free albumin $(0.1 \mathrm{ml}$ of a $25 \%$, wt/vol, water solution) followed by precipitation with $0.1 \mathrm{ml}$ of $2 \mathrm{M}$ perchloric acid. After centrifugation, acid-soluble radioactivity was measured in an aliquot of the supernatant by scintillation counting. For determination of intermediates, the remainder of the incubation mixture was quenched after $60 \mathrm{~min}$ by the addition of $100 \mathrm{ml}$ of $1 \mathrm{M} \mathrm{H}_{2} \mathrm{SO}_{4}$, (see below).
For quantitation of ${ }^{14} \mathrm{CO}_{2}$ production, incubations were performed in glass vials, fitted with rubber caps, containing a $0.4 \mathrm{ml}$ microcentrifuge tube inside a $1.5 \mathrm{ml}$ microcentrifuge tube. After quenching with $100 \mu \mathrm{l}$ of $2 \mathrm{M}$ perchloric acid, $400 \mu$ l of hyamine hydroxide (40\% in methanol) was added to the central microcentrifuge tube and left overnight to ensure complete trapping of ${ }^{14} \mathrm{CO}_{2}$. Total oxidation products were calculated as the sum of acid-soluble products and $\mathrm{CO}_{2}$.

To evaluate ${ }^{14} \mathrm{CO}_{2}$ production by hepatocytes in the presence of substrates other than palmitate, $\left[\mathrm{U}-{ }^{14} \mathrm{C}\right]$ pyruvate or $\left[\mathrm{U}-{ }^{14} \mathrm{C}\right]$ octanoate (specific radioactivity $50 \mathrm{Ci} / \mathrm{mol}$ ) were added to permeabilized cells at a final concentration of $0.1 \mathrm{mM}$. In some experiments, hepatocytes were incubated with etomoxir $(100 \mu \mathrm{mol} / \mathrm{l})$, rotenone $(5 \mathrm{mg} / \mathrm{l})$, antimycin $A$ $(5 \mathrm{mg} / \mathrm{l})$ or sodium cyanide $(1 \mathrm{mmol} / \mathrm{l})$ indicated in each case. Etomoxir is the generic name for $(+)$-2-[6-(4-chlorophenoxy)hexyl]-oxiranecarboxylate, a compound able to inhibit specifically CPT-1 enzyme activity (SigmaAldrich, Milan, Italy). Total oxidation products were calculated as the sum of acid-soluble products and $\mathrm{CO}_{2}$.

Acyl-CoA and acylcarnitines esters were extracted from the cell incubations and analyzed by radio-HPLC. ${ }^{48}$ The identity of each acyl-CoA and acylcarnitine ester produced during the fibroblast incubations was determined by its relative retention time compared with those of standard compounds. Quantification was based on the integrated radioactive peaks after correction for recovery with appropriate internal standard.

Intracellular levels of malonyl-CoA were determined in neutralized perchloric acid cell extracts by a radioenzymatic method as described before. $^{49}$

\section{Measurement of CPT-1 in permeabilized cells}

CPT-1 was measured by using digitonin-permeabilized cells as described by Sleboda et al., ${ }^{50}$ with minor modifications. A total of $10^{6}$ primary human hepatocytes were plated in DMEM with 10\% FBS in six-well plates in triplicate. Before CPT-1 measurement, the medium was removed, and cells were permeabilized and treated with tBid and ZVAD-fmk as specified previously. Then, the hepatocytes were incubated with $700 \mu$ l of assay medium consisting of $50 \mathrm{mM}$ imidazole, $70 \mathrm{mM} \mathrm{KCl}, 80 \mathrm{mM}$ sucrose, $1 \mathrm{mM}$ EGTA, $2 \mathrm{mM} \mathrm{MgCl}_{2}, 1 \mathrm{mM}$ DTT, $1 \mathrm{mM} \mathrm{KCN}, 1 \mathrm{mM} \mathrm{ATP}, 0.1 \%$ fatty acidfree $\mathrm{BSA}, 70 \mu \mathrm{M}$ palmitoyl-CoA and $0.25 \mu \mathrm{Ci}$ of $\mathrm{L}-\left[\right.$ methyl $\left.-{ }^{14} \mathrm{C}\right]$ carnitine, with or without etomoxir $(100 \mu \mathrm{mol} / \mathrm{l})$. After incubation for $5 \mathrm{~min}$ at $37^{\circ} \mathrm{C}$, the reaction was stopped by the addition of $500 \mu$ l of ice-cold $4 \mathrm{M}$ perchloric acid. Cells were then harvested and centrifuged at $13000 \times \mathrm{g}$ for $5 \mathrm{~min}$. The pellet was washed with $500 \mu \mathrm{l}$ of ice-cold $2 \mathrm{mM}$ perchloric acid and centrifuged again. The resulting pellet was resuspended in $800 \mu \mathrm{l}$ of deionized $\mathrm{H}_{2} \mathrm{O}$ and extracted with $400 \mu \mathrm{l}$ of butanol. The butanol phase was counted by liquid scintillation. The assay was linear for up to $7 \mathrm{~min}$ at $37^{\circ} \mathrm{C}$.

\section{Quantitative analysis of cardiolipin in tBid-treated hepatocytes}

Lipids were extracted from cell homogenates $\left(10 \times 10^{6}\right.$ cells/sample) according to Bligh and Dyer ${ }^{51}$ Tetrastearoyl-cardiolipin $(3.6 \mathrm{nmol})$ was added as an internal standard at the initial step of lipid extraction. At the end of procedure, the eluate was dried and redissolved in $0.1 \mathrm{ml}$ of $n$-hexane-ethanol 1:1 (by volume). A measeure of $30 \mu \mathrm{l}$ of this solution were separated by HPLC using a C18-Hypersil $(5 \mathrm{~mm})$ column $\left(150 \times 3.2 \mathrm{~mm}^{2}\right)$ as described previously. ${ }^{52} \mathrm{~A}$ solvent gradient was run from acetonitrile-2-propanol $8: 2$ (by volume) to acetonitrile-2-propanol 
$5: 5$ in $30 \mathrm{~min}$. For peak identification, fractions were collected and processed for measurement of the fatty acid profile.

\section{siRNA-mediated knockdown of Bax and Bak}

Hepatocytes were plated in six-well plates and transfected with Oligofectamine (Invitrogen) according to the manufacturer's protocol. siRNA against Bax and Bak were purchased from Dharmacon's SMARTpool selection. A negative control pool was included in all siRNA experiments. At $48 \mathrm{~h}$ after transfection, cells were split into fresh media for another $24 \mathrm{~h}$ before permeabilization. The expression of Bax and Bak was analyzed by Western blot using a primary anti-Bax (N-20) or anti-Bak (G-23) antibody (Santa Cruz Biotechnology, Milan, Italy) and a secondary HRP-conjugated anti-mouse IgG (Pierce, Milan, Italy). STAT-1 and ISG 15 antibodies were purchased by Delta Biolabs (CA, USA) and Novus Biologicals (CO, USA), respectively.

\section{Hepatocyte transfection with Bcl-2}

Hepatocytes were transfected with either Bcl-2 cDNA-containing neomycin-selectable pSFFVneo/Bcl-2 plasmid (HEP/Bcl-2 cells), or control neomycin-selectable pBK-CMV plasmid (HEP/neo cells) using Lipofectin (Life Technologies Inc., Gaithersburg, MD, USA) following the manufacturer's instructions. Several positive HEP/Bcl-2 and HEP/neo clones were selected and expanded. Cells were routinely maintained in a neomycin selection culture medium. The expression of Bcl-2 was confirmed by Western blot analysis using a primary anti-Bcl-2 antibody (clone Bcl-2/100 at 1:1000 dilution; Pharmingen, Milan, Italy) and a secondary HRP-conjugated anti-mouse IgG (1:5000 dilution; Pierce, Milan, Italy).

\section{Evaluation of interaction of CPT-1 with tBid by immunoprecipitation}

Immunoprecipitation of $\mathrm{tBid} / \mathrm{CPT}-1$ complexes was performed on hepatocytes or isolated mitochondria using a method described previously. ${ }^{53}$ Hepatocytes were permeabilized and subjected or not to tBid treatment. Then, mitochondria were isolated and incubated with $10 \mathrm{mM}$ bismaleimidohexane $(\mathrm{BMH})$ crosslinker. The mitochondrial pellets were lysed in RIPA buffer. The extracts were directly used for immunoblot analysis of $\mathrm{tBid}$, or subjected to immunoprecipitation with anti-CPT-1 antibody followed by detection of tBid in the precipitates by immunoblotting.

In another set of experiments, mitochondria were isolated from hepatocytes, incubated with $20 \mathrm{ng} / \mathrm{ml}$ tBID for $30 \mathrm{~min}$ at $30^{\circ} \mathrm{C}$, treated with $10 \mathrm{mM}$ BMH crosslinker and then lysed in RIPA buffer. Immunoprecipitation (with anti-CPT-1 antibody) and/or immunoblotting (with anti-tBid antibody) were performed as described before.

The composition of RIPA buffer was (in $\mathrm{mM}$ ): $150 \mathrm{NaCl}, 1 \mathrm{MgCl}_{2}, 1$ EGTA, $10 \beta$-mercaptoethanol, 15 Tris- $\mathrm{HCl}, \mathrm{pH} 7.4$, containing $0.5 \%$ sodium deoxycholate, $0.2 \%$ SDS and $1 \%$ Triton $\mathrm{X}-100$.

\section{References}

1. Scheffler IE (2001) A century of mitochondrial research: achievements and perspectives. Mitochondrion 1: 3-31

2. Kroemer $G$ and Reed JC (2000) Mitochondrial control of cell death. Nat. Med. 6: $513-519$
3. van Loo G, Saelens X, van Gurp M, MacFarlane M, Martin SJ and Vandenabeele $P$ (2002) The role of mitochondrial factors in apoptosis: a Russian roulette with more than a bullet. Cell Death Differ. 9: 1031-1042

4. Majewski N, Nogueira V, Brooks Robey R and Hay N (2004) Akt inhibits apoptosis downstream of Bid cleavage via a glucose-dependent mechanism involving mitochondrial hexokinases. Mol. Cell. Biol. 24: 730-740

5. de Pablo MA, Susin SA, Jacotot E, Larochette N, Costantini P, Ravagnan L, Zamzami N and Kroemer G (1999) Palmitate induces apoptosis via a direct effect on mitochondria. Apoptosis 4: 81-87

6. Paumen MB, Ishida Y, Muramatsu M, Yamamoto M and Honjo T (1997) Inhibition of carnitine palmitoyltransferase I augments sphingolipid synthesis and palmitate-induced apoptosis. J. Biol. Chem. 272: 3324-3329

7. Gottlob K, Majewski N, Kennedy S, Kandel E, Brooks Robey R and Hay N (2001) Inhibition of early apoptotic events by Akt/PKB is dependent on the first committed step of glycolysis and mitochondrial hexokinase. Genes Dev. 15: $1406-1418$

8. Bogucka K, Wroniszewska A, Bednarek M, Duszynski J and Wojtczak L (1990) Energetics of Ehrlich ascites mitochondria: membrane potential of isolated mitochondria and mitochondria within digitonin-permeabilized cells. Biochim. Biophys. Acta 1015: 503-509

9. Saks VA, Veksler VI, Kuznetsov AV, Kay L, Sikk P, Tiivel T, Tranqui L, Olivares J, Winkler K, Wiedemann F and Kunz WS (1998) Permeabilized cell and skinned fiber techniques in studies of mitochondrial function in vivo. Mol. Cell. Biochem. 184: 81-100

10. Niot I, Pacot F, Bouchard P, Gresti J, Bernard A, Bezard J and Clouet P (1994) Involvement of microsomal vesicles in part of the sensitivity of carnitine palmitoyltransferase I to malonyl-CoA inhibition in mitochondrial fractions of rat liver. Biochem. J. 304: 577-584

11. Mootha VK, Wei MC, Buttle KF, Scorrano L, Panoutsakopoulou V, Mannella CA and Korsmeyer SJ (2001) A reversible component of mitochondrial respiratory dysfunction in apoptosis can be rescued by exogenous cytochrome c. EMBO J. 20: 661-671

12. Waterhouse NJ, Goldstein JC, von Ahsen O, Schuler M, Newmeyer DD and Green DR (2001) Cytochrome c maintains mitochondrial transmembrane potential and ATP generation after outer mitochondrial membrane permeabilization during the apoptotic process. J. Cell Biol. 153: 319-328

13. Broadway NM and Saggerson ED (1997) Effect of membrane environment on the activity and inhibitability by malonyl-CoA of the carnitine acyltransferase of hepatic microsomal membranes. Biochem. J. 322: 435-440

14. MCGarry JD and Brown NF (2000) Reconstitution of purified, active and malonyl-CoA-sensitive rat liver carnitine palmitoyltransferase I: relationship between membrane environment and malonyl-CoA sensitivity. Biochem. J. 349: $179-187$

15. Paumen MB, Ishida $Y$, Han $H$, Muramatsu $M$, Eguchi $Y$, Tsujimoto $Y$ and Honjo $T$ (1997) Direct interaction of the mitochondrial membrane protein carnitine palmitoyltransferase I with Bcl-2. Biochem. Biophys. Res. Commun. 231: 523-525

16. Yi X, Yin XM and Dong Z (2003) Inhibition of Bid-induced apoptosis by Bcl-2. tBid insertion, Bax translocation, and Bax/Bak oligomerization suppressed. J. Biol. Chem. 278: 16992-16999

17. Hardy S, El-Assaad W, Przybytkowski E, Joly E and Prentki M (2003) Saturated fatty acid-induced apoptosis in MDA-MB 231 breast cancer cells. J. Biol. Chem. 278: $31861-31870$

18. Furuno $T$, Kanno $T$, Arita $K$, Asami M, Utsumi T, Doi $Y$, Inoue $M$ and Utsumi $k$ (2001) Roles of long chain fatty acids and carnitine in mitochondrial membrane permeability transition. Biochem. Pharmacol. 62: 1037-1046

19. Kim T-H, Zhao Y, Barber MJ, Kuharsky DK and Yin X-M (2000) Bid-induced cytochrome $c$ release is mediated by a pathway independent of mitochondrial permeability transition pore and Bax. J. Biol. Chem. 275: 39474-39481

20. Ricci J-E, Gottlieb RA and Green DR (2003) Caspase-mediated loss of mitochondrial function and generation of reactive oxygen species during apoptosis. J. Cell Biol. 160: 65-75

21. Voisine C, Craig EA, Zufall N, von Ahsen O, Pfanner N and Voos W (1999) The protein import motor of mitochondria: unfolding and trapping of preproteins are distinct and separable functions of matrix Hsp70. Cell 97: 565-574

22. Degli Esposti M (2004) Mitochondria in apoptosis: past, present and future. Biochem. Soc. Trans. 32: 493-495

23. Kim TH, Zhao Y, Ding WX, Shin JN, He X, Seo YW, Chen J, Rabinowich $\mathrm{H}$, Amoscato AA and Yin XM (2004) Bid-cardiolipin interaction at mitochondrial 
contact site contributes to mitochondrial cristae reorganization and cytochrome c release. Mol. Cell. Biol. 15: 3061-3072

24. Wright MM, Howe AG and Zaremberg V (2004) Cell membranes and apoptosis: role of cardiolipin, phosphatidylcholine, and anticancer lipid analogues. Biochem. Cell Biol. 82: 18-26

25. Newmeyer DD and Ferguson-Miller S (2003) Mitochondria: releasing power for life and unleashing the machineries of death. Cell 112: 481-490

26. Wei MC, Zong WX, Cheng EH, Lindsten T, Panoutsakopoulou V, Ross AJ, Roth KA, MacGregor GR, Thompson CB and Korsmeyer SJ (2001) Proapoptotic Bax and Bak: a requisite gateway to mitochondrial dysfunction and death. Science 292: 727-730

27. Bridge AJ, Pebernard S, Ducraux A, Nicoulaz AL and Iggo R (2003) Induction of an interferon response by RNAi vectors in mammalian cells. Nat. Genet. 34 263-264

28. de Veer MJ, Holko M, Frevel M, Walker E, Der S, Paranjpe JM, Silverman RH and Williams BR (2001) Functional classification of interferon-stimulated genes identified using microarrays. J. Leukocyte Biol. 69: 912-920

29. Levade T, Hannun Y and Spiegel S (2002) Lipids and apoptosis: foreword. Biochim. Biophys. Acta 1015: 51

30. Berge K, Tronstad KJ, Bohov P, Madsen L and Berge RK (2003) Impact of mitochondrial $\beta$-oxidation in fatty acid-mediated inhibition of glioma cell proliferation. J. Lipid Res. 44: 118-127

31. Radin NS (2001) Killing cancer cells by poly-drug elevation of ceramide levels A hypothesis whose time has come? Eur. J. Biochem. 268: 193-204

32. Wieckowski MR, Brdiczka D and Wojtczak $L$ (2000) Long-chain fatty acids promote opening of the reconstituted mitochondrial permeability transition pore. FEBS Lett. 484: 61-64

33. Hanada K (2003) Serine palmitoyltransferase, a key enzyme of sphingolipid metabolism. Biochim. Biophys. Acta 1632: 16-30

34. Giordano A, Calvani M, Petillo O, Carteni M, Melone MR and Peluso G (2003) Skeletal muscle metabolism in physiology and in cancer disease. J. Cell. Biochem. 90: 170-186

35. Peluso G, Nicolai R, Reda E, Benatti P, Barbarisi A and Calvani M (2000) Cancer and anticancer therapy-induced modifications on metabolism mediated by carnitine system. J. Cell. Physiol. 182: 339-350

36. Eaton $S$ (2002) Control of mitochondrial $\beta$-oxidation flux. Progress Lipid Res. 41: 197-239

37. Degli Esposti M (2002) Lipids, cardiolipin and apoptosis: a greasy license to kill. Cell Death Differ. 9: 234-236

38. Esposti MD, Cristea IM, Gaskell SJ, Nakao Y and Dive C (2003) Proapoptotic Bid binds to monolysocardiolipin, a new molecular connection between mitochondrial membranes and cell death. Cell Death Differ. 10 $1300-1309$
39. Lutter M, Perkins GA and Wang X (2001) The pro-apoptotic Bcl-2 family member tBid localizes to mitochondrial contact sites. BMC Cell Biol. 2: 22-30

40. Sorice M, Circella A, Cristea IM, Garofalo T, Di Renzo L, Alessandri C, Valesini $\mathrm{Gm}$ and Esposti MD (2004) Cardiolipin and its metabolites move from mitochondria to other cellular membranes during death receptor-mediated apoptosis. Cell Death Differ. 11: 1133-1145

41. Liu J, Weiss A, Durrant D, Chi NW and Lee RM (2004) The cardiolipin-binding domain of Bid affects mitochondrial respiration and enhances cytochrome $C$ release. Apoptosis 9: 533-541

42. Fraser F, Corstorphine CG and Zammit VA (1997) Topology of carnitine palmitoyltransferase I in the mitochondrial outer membrane. Biochem. J. 323: 711-718

43. Cheng EH, Wei MC, Weiler S, Flavell RA, Mak TW, Lindsten T and Korsmeyer SJ (2001) Bcl-2, Bcl-x(I) sequester BH3 domain-only molecules preventing Bax- and Bak-mediated mitochondrial apoptosis. Mol. Cell 8: 705-711

44. Shepherd D and Garland PB (1969) Citrate synthase from rat liver. Methods Enzymol. 13: 11-16

45. Vassault A (1983) Lactate dehydrogenase-UV-method with pyruvate and NADH In Methods of Enzymatic Analysis Bergmayer HU, Grassel M (eds) (Weinheim: Verlag Chemie) pp. 118-126

46. Gross A, Pilcher K, Blachly-Dyson E, Basso E, Jockel J, Bassik MC, Korsmeyer SJ and Forte M (2000) Biochemical and genetic analysis of the mitochondrial response of yeast to Bax and Bcl-xl. Mol. Cell. Biol. 20: 3125-3136

47. Lee AC, Zizi M and Colombini M (1994) Beta-NADH decreases the permeability of the mitochondrial outer membrane to ADP by a factor of 6 . J. Biol. Chem. 269: 30974-30980

48. Poufarzam M and Bartlett K (1991) Synthesis, characterization and high performance liquid chromatography of $\mathrm{C}_{6}-\mathrm{C}_{16}$ dicarboxylyl-mono-coenzyme $A$ and mono-carnitine esters. J. Chromatogr. 57: 253-276

49. Beynen AC, Vaartjes WJ and Geelen MJ (1979) Opposite effects of insulin and glucagon in acute hormonal control of hepatic lipogenesis. Diabetes 28 : 828-835

50. Sleboda J, Risan KA, Spydevold $\varnothing$ and Bremer J (1999) Short-term regulation of carnitine palmitoyltransferase I in cultured rat hepatocytes: spontaneous inactivation and reactivation by fatty acids. Biochim. Biophys. Acta 750: 244-252

51. Bligh EG and Duer WJ (1959) A rapid method of total lipid extraction and purification. Can. J. Biochem. Physiol. 37: 911-917

52. Schlame M, Shanske S, Doty S, Konig T, Sculco T, DiMauro S and Blanck TJJ (1999) Microanalysis of cardiolipin in small biopsies including skeletal muscle from patients with mitochondrial disease. J. Lipid Res. 40: 1585-1592

53. Cheng EH, Levine B, Boise LH, Thompson CB and Hardwick JM (1996) Baxindependent inhibition of apoptosis by Bcl-XL. Nature 379: 554-556 